\title{
IN VITRO WOUND HEALING AND ANTIMICROBIAL PROPERTY OF COTTON FABRICS COATED OPTIMIZED SILVER NANOPARTICLES SYNTHESIZED USING PELTOPHORUM PTEROCARPUM LEAF EXTRACTS
}

\author{
ANNAMALAI P*, BALASHANMUGAM P, KALAICHELVAN PT \\ Centre for Advanced Studies in Botany, University of Madras, Chennai, Tamil Nadu, India. Email: annaias1960@gmail.com \\ Received: 06 April 2019, Revised and Accepted: 26 June 2019
}

\begin{abstract}
Objective: The present study was aimed to study at investigating the antibacterial potential of silver nanoparticles (AgNPs) coated cotton fabrics against different pathogens and also for their wound healing property using fibroblasts cells.

Materials and Methods: The leaf extracts of Peltophorum pterocarpum were used for the synthesis of AgNPs and were characterizing using ultravioletvisible spectrophotometer, transmission electron microscopy, energy dispersive X-ray (EDX) spectroscopy, dynamic light scattering analysis, and zeta potential measurement. The AgNPs were coated on cotton fabrics and tested for their antibacterial efficacy using agar well diffusion method. The wound healing property of synthesized AgNPs was tested using fibroblast 3T3 cells.

Results: The plant extracts of P. pterocarpum were utilized for AgNPs. The optimum condition for synthesizing AgNPs was found to be 1 mg/ml plant concentration, $7 \mathrm{pH}, 1 \mathrm{mM}$ silver nitrate concatenation, and incubation temperature of $37^{\circ} \mathrm{C}$. The shape of synthesized AgNPs was found to be spherical with an average size between 20 and $50 \mathrm{~nm}$, and elemental silver peaks were confirmed by EDX spectrum. The cotton fabrics coated with AgNPs show good zone of inhibition against all the tested pathogens and the treated fabrics were also characterized using scanning electron microscope which reveals the presence of AgNPs on the fabrics. The scratch assay reveals that the AgNPs have good wound healing activity when tested against fibroblast 3T3.
\end{abstract}

Conclusion: The present results conclude that the synthesized AgNPs have good stability with potent antimicrobial activity when coated with cotton fabrics. The AgNPs also found to have good activity significant wound healing activity when tested using fibroblast cells.

Keywords: Silver nanoparticles treated cotton fabrics, Transmission electron microscopy, Scratch assay.

(C) 2019 The Authors. Published by Innovare Academic Sciences Pvt Ltd. This is an open access article under the CC BY license (http://creativecommons. org/licenses/by/4. 0/) DOI: http://dx.doi.org/10.22159/ajpcr.2019.v12i8.33483

\section{INTRODUCTION}

Nanoparticles have gained much importance among researchers from various branches of science in the last decade due to their potential applications in different fields. Smaller size range and high surface to volume ratio are the main reasons for this wide application of nanoparticles [1]. Among the different noble metal nanoparticles, silver nanoparticles (AgNPs) have major application in the medical science due to their exceptional physical and chemical properties such as stability, electrical conductivity, catalytic, and antibacterial activity [2].

Various physical, chemical, and biological processes are utilized for the synthesis of nanoparticles. Both physical and chemical methods have major limitations such as high temperature, pressure, and chemical contamination during the process of synthesis of metal nanoparticles. However, green or biological synthesis of metal nanoparticles has significant advantages, eco-friendliness, large scale production, costeffectiveness, less contamination, etc. [3]. Recently, several researchers have been exploiting various microbes and plants for the synthesis of metal nanoparticles, especially, AgNPs [4,1]. The main advantage of using plant and plant-related components for the synthesis of AgNPs includes capping and stabilizing property [5]. Metabolites isolated from microorganisms and plants have a tendency to reduce the metal compounds to their respective nanomaterials. Especially, in the case of plant compounds, polysaccharides, enzymes, proteins, alkaloids, tannins, and vitamins could play a key role in the reduction of metals to nanoparticles and also stabilize them [6,7]. The reduced silver particles $(\mathrm{Ag}+)$ cause the change in secondary structure and formation of silver nuclei and as they are trapping the Ag+ on the protein surface because of electrostatic interaction. Further reduction in silver ions proceeds with the silver nuclei growth, results in the accumulation of nuclei and thus leads to the AgNP production. Among them, hydrophilic compounds such as organic acids and flavones involve immediate reduction and production of AgNPs, while anthraquinone and emodin compounds reduce the silver after tautomerization process. Interestingly, different plant sources provide several extract compositions which could be essential as a reducing agent for the silver without elaborate process [8].

Antimicrobial property is one of the main applications of AgNPs in the medical field. The wound healing property of AgNPs has been reported to control the colonization and proliferation of the pathogens in the wounded area [9]. The antibacterial activity of AgNPs depends on their contact surface area and interaction with other organic and inorganic molecules [10]. AgNPs have unique physicochemical properties which confer them as a good source for the product developments against multidrug-resistant microorganisms [11]. Moreover, the AgNPs are non-toxic to human beings at their low concentration. In recent times, the application of AgNPs to cotton fabric has attained a great deal because of its wound healing property [12]. At present, the AgNPs based wound dressing has been widely used for the treatment of open wounds [13]. The presence of AgNPs damages the DNA of pathogenic bacteria, thereby inhibiting their replication process. Previous research has reported that the healing property of AgNPs on sterile wounds in rat models was due to their anti-inflammatory action and it also enhances the granulation phases of healing leading to epidermal recovery [14-16].

Our earlier studies show that AgNPs synthesized using Peltophorum pterocarpum leaf extracts showed the potential antimicrobial property 
when tested against different human pathogens. In the present study, we aimed at determining the antibacterial potential of AgNPs coated cotton fabrics against different pathogens and also evaluated for their wound healing property using fibroblasts cells.

\section{MATERIALS AND METHODS}

\section{Chemicals}

For the present study, silver nitrate $\left(\mathrm{AgNO}_{3}\right)$ was purchased from Sigma-Aldrich; nutrient agar, Muller-Hilton Agar from HiMedia, India, dimethyl sulfoxide and other analytical chemicals were procured from Merck, Ltd. India.

\section{Preparation of plant leaf extract and synthesis of AgNPs}

Fresh and healthy leaves of $P$. pterocarpum were collected and washed with running water to remove the surface impurities on the leaves. The identification of plant materials was performed at the Centre for Advanced Studies in Botany, and the specimen of plants was numbered as KA9 and deposited in our laboratory for future reference [17]. Then, the leaves $(10 \mathrm{~g})$ were mixed with $100 \mathrm{ml}$ of deionized water and kept in a rotary shaker for $48 \mathrm{~h}$. The extracts were then collected by passing it through Whatman No.1 filter paper and stored at $4^{\circ} \mathrm{C}$ for further analysis. To $1 \mathrm{ml}$ of leaf extract, $9 \mathrm{ml}$ of $1 \mathrm{mM} \mathrm{AgNO}_{3}$ solution was mixed and kept in the dark condition for $24 \mathrm{~h}$ at room temperature. The change in the color of the solution to brown color indicates the AgNPs formation $[17,18]$.

\section{Ultraviolet-visible (UV-Vis) spectra analysis}

The formation of AgNPs in the solution was determined and confirmed by UV-Vis spectra analysis using double beam Perkin-Elmer UV-Vis spectrophotometer at a resolution of $1 \mathrm{~nm}$. The spectral range from 200 to $800 \mathrm{~nm}$ at a scan speed of $450 \mathrm{~nm} / \mathrm{min}$ was used to analyze the synthesized AgNPs.

\section{Optimization of AgNPs synthesis}

In the present study, different parameters such as the effect of various concentrations of leaf extracts, different temperature, $\mathrm{pH}$, and effect of various concentrations of $\mathrm{AgNO}_{3}$ were analyzed at the optimum condition for the synthesis of AgNPs. The reaction temperature, such as $23,30,37,43$, and $50^{\circ} \mathrm{C}$, was maintained using the water bath. The $\mathrm{pH}$ of the reaction was also optimized with $\mathrm{pH}$ ranging from 4, 5, 6, 7, 8, and 9. Similarly, the concentration of $\mathrm{AgNO}_{3} 1,2,3,4$, and $5 \mathrm{mM}$ ) and plant leaf extracts $(1,2,3,4$, and $5 \mathrm{mg} / \mathrm{mL})$ was also optimized for the synthesis of AgNPs. The stability of the synthesized AgNPs was also determined from $12 \mathrm{~h}$ to 3 months. During the optimization studies, the AgNPs formation was monitored and measured spectrophotometrically using UV-Vis spectrophotometer in the range of $200-800 \mathrm{~nm}$.

\section{Transmission electron microscopy (TEM)}

The TEM study was performed to determine the size and shape of the synthesized AgNPs. A drop of synthesized AgNPs was placed on the carbon coated grid and allowed to dry by placing it in the desiccators. The grid coated with the synthesized AgNPs was analyzed using TEM microscope (FEI Tecnai) at $100 \mathrm{kV}$ equipped with energy dispersive X-ray (EDX) spectroscopy to study the elemental composition [19].

\section{Dynamic light scattering (DLS) analysis and zeta potential} measurements

To determine the particle size distribution of the synthesized nanoparticles, the synthesized AgNPs were subjected to DLS analysis using Merck 2423. The stability of the synthesized AgNPs was determined using zeta potential measurement. The synthesized AgNPs were subjected for zeta potential measurement using zeta meter (Malvern zeta seizer 2000, Malvern), and the values were determined ranging from higher than $+30 \mathrm{mV}$ to lower than $-30 \mathrm{mV}$.

\section{Incorporation of synthesized AgNPs on cotton fabrics}

For the present study, cotton fabrics of the size of $1 \times 1 \mathrm{~cm}^{2}$ were taken and washed with deionized water and dried. The pre-sterilized fabrics were then impregnated with AgNps solution (100 ppm) under aseptic conditions and were dried at $50^{\circ}$ overnight. The AgNPs incorporated cotton fabrics and untreated cotton fabrics were characterized under the scanning electron microscope (SEM) (Hitachi S-3400N) to study their morphological changes [19].

\section{Antibacterial activity of AgNPs-cotton fabric}

The antibacterial evaluation of AgNPs-cotton fabric was performed by agar diffusion assay on nutrient agar plates. For the present study, four different pathogens, namely, Staphylococcus aureus (MTCC-96), Bacillus subtilis (MTCC-441), Escherichia coli (MTCC-443), and Pseudomonas aeruginosa (MTCC-1688) were procured from the Institute of Microbial Technology, Chandigarh, India. Briefly, an overnight culture of four different strains was lawn cultured in the sterile nutrient agar plates. The untreated and cotton fabrics coated with AgNPs were then placed gently on the plates inoculated with the test strains. The plates were then incubated for $24 \mathrm{~h}$ at $37^{\circ} \mathrm{C}$, and the zone around the AgNPs-cotton fabric was calculated and recorded.

\section{In vitro wound scratch assay}

The modified in vitro wound scratch assay was performed based on the previously reported method [20]. In the present study, fibroblast $3 \mathrm{~T} 3$ cells were procured from National Centre for Cell Sciences, Pune, India. The cells were seeded in 6-well plates $\left(8 \times \mathrm{s} 10^{5}\right.$ cells/well $)$ and grown until it reached a confluence of $90 \%$. A wound was generated using a micropipette tip $(200 \mu \mathrm{l})$, and the cell debris was removed by washing with fresh medium. Then, the wound was treated with $60 \mu \mathrm{g} / \mathrm{mL}$ biologically synthesized AgNPs and $60 \mu \mathrm{g} / \mathrm{mL}$ of the commercial drug, Cipladine (Positive control) separately. The plate was then incubated for $24-96 \mathrm{~h}$ at $37^{\circ} \mathrm{C}$ in a humidified atmosphere with a supply of $5 \% \mathrm{CO}_{2}$. The untreated cells without scratch were maintained as a negative control. The scratch wound closure was observed using an inverted microscope (Magnus INVI, Noida), and the pictures of migrations of the treated cells were captured at various points of time starting from $0^{\text {th }}$ day to $4^{\text {th }}$ day (static imaging). The closure of the wound scratch was determined by calculating the difference between the wound width at $\mathrm{t} 0$ and $\mathrm{t} 2$, using the Image J processing software. The scratch closure rate (SCR) was calculated based on the following formula [21]:

$\mathrm{SCR}=([\mathrm{At} 0-\mathrm{At} 2] / \mathrm{At} 0) \times 100$

Where At $0=S c r a t c h$ area at time 0 ; At $2=S c r a t c h$ area at $2^{\text {nd }}$ day. Results were reported as the mean of three independent experiments \pm standard deviation.

\section{RESULTS AND DISCUSSION}

In the current scenario, different methods have been reported for the synthesis of nanoparticles, which mostly depend on the cost, time, and future applications of nanoparticles. Among the various methods, plant-based syntheses of nanoparticles have been found to be efficient in the medical field because of their excellent properties. The abundance of secondary metabolites in plant components contributes their medicinal property that imparts the functional value to the nanoparticles synthesized from plant extracts. The composite of plant metabolite-nanoparticle is much more efficient than their individual activity. The AgNPs are extensively analyzed nanoparticles in various clinical and medical fields [22]. In the present study, plant leaf extracts of $P$. pterocarpum were used to synthesize the AgNPs and application toward antibacterial and wound healing properties were evaluated against various pathogens.

\section{Synthesis of AgNPs using plant leaf extracts}

The utilization of plant extracts for the reduction of silver ions to AgNps was reported by various researchers from different leaf extracts such as Mukia scabrella [23], Morinda citrifolia [23], Iresine herbstii [24], Azadirachta indica [25,5], and Ocimum sanctum [26,27]. The formation of AgNPs using the leaf extracts of $P$. pterocarpum was initially confirmed by the presence of an initial color change to brown color. Further, the maximum absorption peak of $413 \mathrm{~nm}$ was determined using UV- 
Vis spectrophotometer, which confirms the synthesis of AgNPs in the reaction mixture. The change in the color is due to the excitation of surface plasmon vibrations in the synthesized AgNPs. A similar finding was reported by researchers who have also synthesized AgNPs using different plant leaf extracts. They also reported the maximum absorption peak in the range of $430-440 \mathrm{~nm}$ for the formation of AgNPs when the aqueous extracts were treated with $1 \mathrm{mM} \mathrm{AgNO}_{3}[28,18]$.

The mechanism of nanoparticles formation using plant extracts is not clearly understood. However, reports suggest that the major constituents responsible for the reduction of $\mathrm{AgNO}_{3}$ to $\mathrm{AgNPs}$ have been found to be secondary metabolites. The various components of the crude extracts from plant such as alkaloids, flavonoids, terpenoids, and phenolic compounds play the major role in the reduction of ionic metal to metallic nanoparticles. Thus, optimizing the biosynthesis process using different parameters also plays a major role in controlling the size and shape of the synthesizing nanoparticles $[29,30]$

\section{Optimization of AgNPs synthesis}

Effect of plant concentration on AgNPs synthesis

Different parameters have been optimized for the ideal synthesis of AgNPs using the P. pterocarpum leaf extract. The different parameters such as the effect of different temperature, $\mathrm{pH}$, concentration of $\mathrm{AgNO}_{3}$, and plant material have been analyzed and studied for their important role in the yield of AgNPs. The AgNPs have been synthesized using a different concentration of leaf extracts ranging from $1 \mathrm{mg}$ to $5 \mathrm{mg} / \mathrm{ml}$.

The synthesis of AgNPs at different concentrations of leaf extract such as $1-5 \mathrm{mg} / \mathrm{mL}$ using $1 \mathrm{mM}$ of $\mathrm{AgNO}_{3}$ was studied. The results show that the increase in the concentration of plant extract has supported the synthesis of AgNps; however, $1 \mathrm{mg} / \mathrm{mL}$ was found to produce a stable synthesis of AgNPs with maximum absorption spectra at $445 \mathrm{~nm}$. Similar results were reported in literature, which confirms the formation of AgNPs in the reaction medium [31]. If we increase the leaf extract concentration to $3-5 \mathrm{mg} / \mathrm{mL}$, there is an increase in the intensity of absorption of AgNPs synthesized, as presented in Fig. 1. The slight variations in the values of absorbance signify that the changes are the particle size [32].

\section{Effect of temperature on AgNPs synthesis}

The effect of different temperature on AgNPs has been analyzed. Fig. 2 shows the UV-vis spectrum of synthesized AgNPs at a different temperature. The spectrum clearly reveals that the absorbance increases with an increase in the reaction temperature. The low level of AgNPs aggregation can be found when the temperature is exponentially increased. However, at a specific temperature $\left(50^{\circ} \mathrm{C}\right)$, the nanoparticles may aggregate easily and the result of crystal growth around the nucleus shows a decrease in absorption value [18]. In the present study, the synthesis of stable AgNPs was observed when the temperature was maintained at $37^{\circ} \mathrm{C}$.

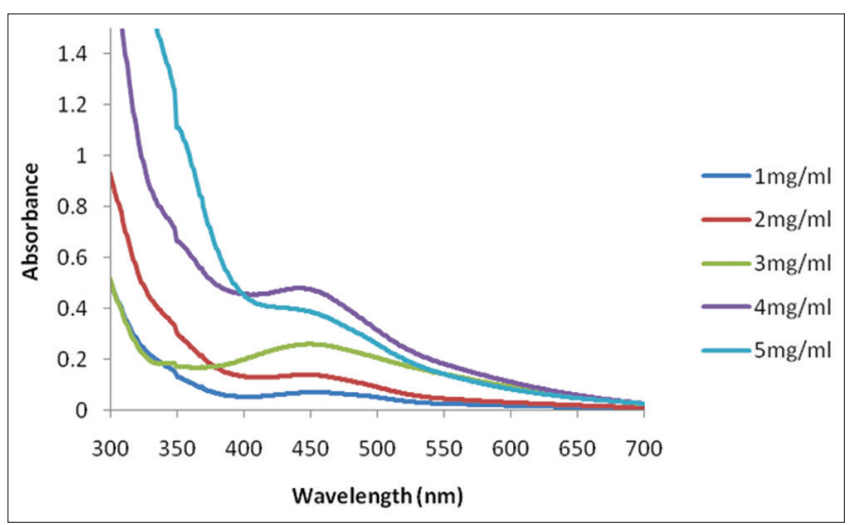

Fig. 1: Ultraviolet-visible spectrum of the silver nanoparticles synthesized using a different concentration of plant extract
Effect of $\mathrm{pH}$ on AgNPs synthesis

Stability of AgNPs on different days was optimized. The rate of AgNPs formation increased at the higher temperature. Similarly, the other physical parameter such as the influence of $\mathrm{pH}$ on the formation of AgNPs was also studied. In general, the acidic condition inhibits the AgNPs formation while basic $\mathrm{pH}$ induces the nanoparticle synthesis. In the present study, $\mathrm{pH}$ varying from 4 to 9 was studied for the formation of AgNPs using leaf extracts. The results show that at lower $\mathrm{pH}$ the formation of AgNPs was found to be affected, and the major peak with good intensity was not observed. However, the increase in $\mathrm{pH}$ between 5 and 9 results in the formation of AgNPs with maximum absorption value (Fig. 3). Proton concentration in the acidic medium might be the reason for the decreased reducing power of plant secondary metabolite. At higher $\mathrm{pH}$, the abundance of a functional group for silver binding causes a higher number of AgNPs formation with small diameters. Earlier reports suggest that the ionization of plant components such as phenolic compounds and tannins in the plant extracts could be affected during the adjustment of $\mathrm{pH}$, thus resulting in varying size of AgNPs [33].

\section{Effect of $\mathrm{AgNO}_{3}$ concentration on AgNPs synthesis}

Similarly, the increase in the concentration of $\mathrm{AgNO}_{3}$ from $1 \mathrm{mM}$ to $5 \mathrm{mM}$ was also studied. The results showed that the increase in absorbance of the synthesized AgNPs when the concentration of $\mathrm{AgNO}_{3}$ was increased from $1 \mathrm{mM}$ to $5 \mathrm{mM}$ (Fig. 4). The maximum absorption peak varies between 430 and $460 \mathrm{~nm}$ when the temperature was maintained between $23^{\circ} \mathrm{C}$ and $50^{\circ} \mathrm{C}$. A similar observation was also reported by various researchers who studied the effect of reaction temperature on AgNPs synthesis. A few reports also showed that an increase in particle size has occurred when the incubation temperature was increased beyond $60^{\circ} \mathrm{C}$ resulting in aggregation of the smaller nanoparticles.

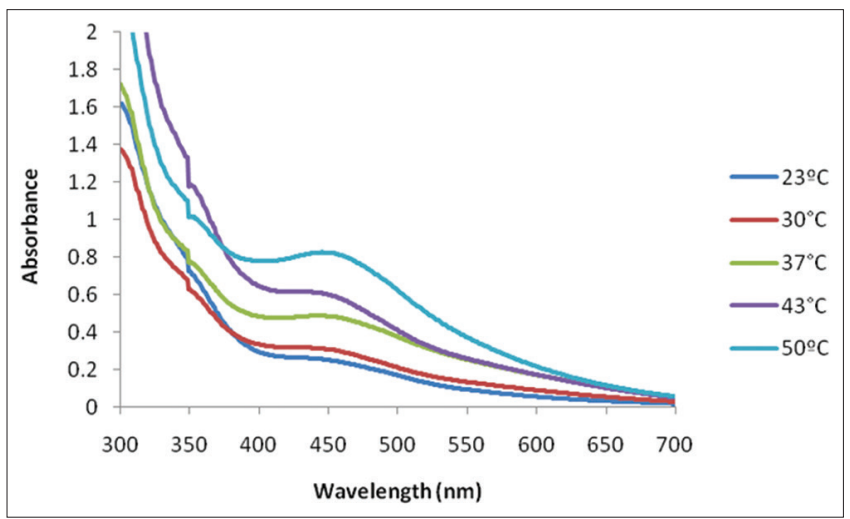

Fig. 2: Ultraviolet-visible spectrum of the silver nanoparticles synthesized at the different reaction temperature

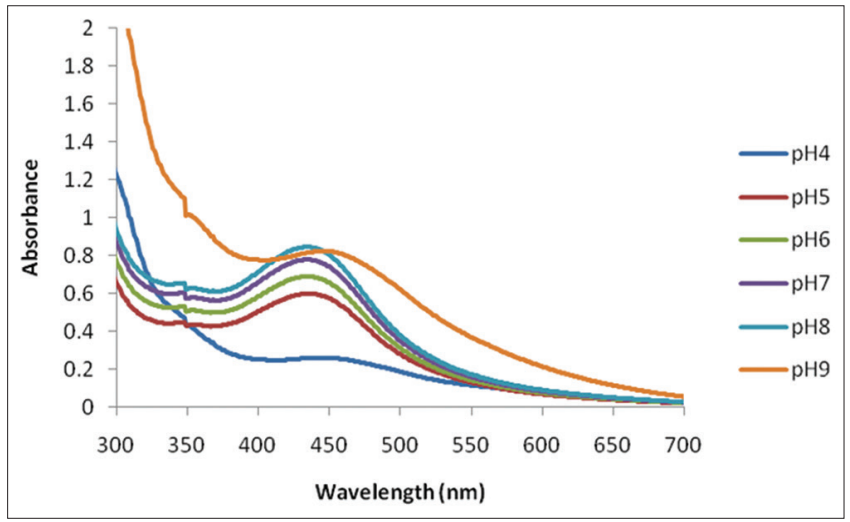

Fig. 3: Ultraviolet-visible spectrum of the silver nanoparticles synthesized at different $\mathrm{pH}$ 
Interestingly, the decrease in nanoparticle size may also occur when the temperature was maintained at high, which may be due to increased reaction rate $[34,5]$.

\section{Stability of AgNPs synthesis}

The stability of the AgNPs was also studied by measuring the maximum absorption spectra at different intervals from $12 \mathrm{~h}$ to 3 months. The results showed that the synthesized AgNPs found to be stable even up to 3 months (Fig. 5), where the maximum absorption was found to be between 420 to $430 \mathrm{~nm}$. Earlier studies reported that the plant metabolites may also have an effect on stability of the synthesized nanoparticles [29]. The formation of monodispersed nanoparticles using the plant leaf extract C. roxburghii was reported by Balashanmugam and co-workers. They investigated the stability of AgNPs by recording the maximum adsorption spectra for 2 months and found that there was no alteration in the absorption peaks even after two months of AgNPs formation which corroborate our results findings [19].

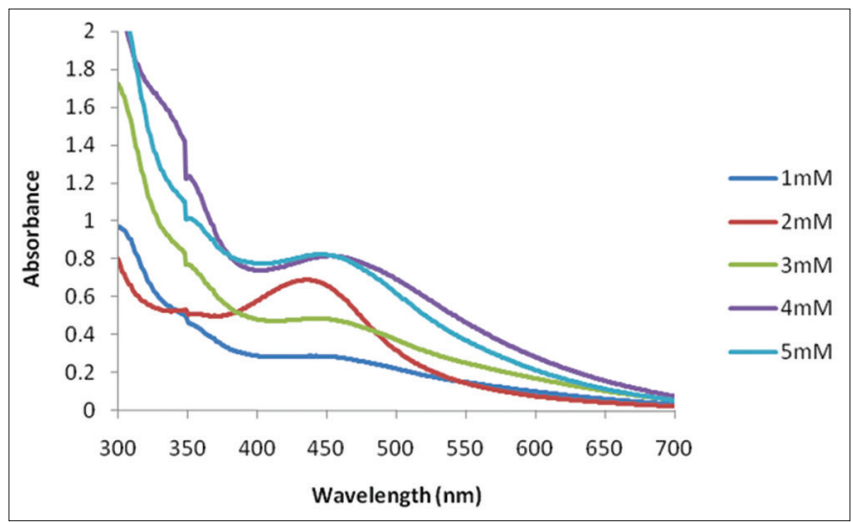

Fig. 4: Ultraviolet-visible spectrum of the silver nanoparticles synthesized at different concentration of silver nitrate

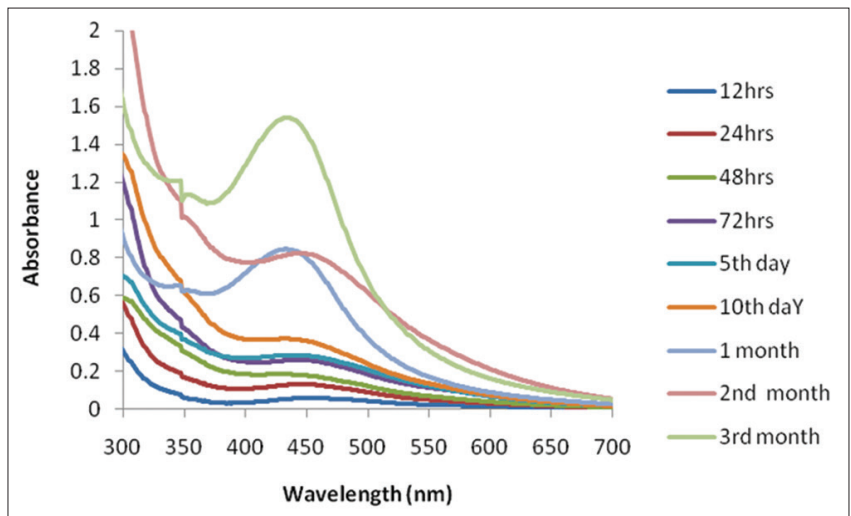

Fig. 5: Ultraviolet-visible spectrum of the silver nanoparticles at different time durations

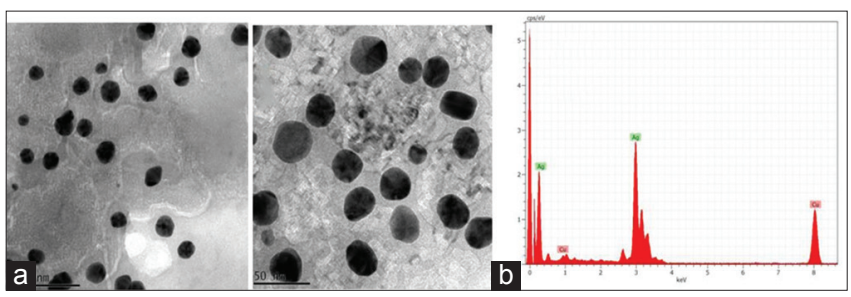

Fig. 6: (a) Transmission electron microscopy and (b) energy dispersive X-ray analysis of synthesized silver nanoparticles
Characterization of synthesized AgNPs

TEM analysis of synthesized AgNPS

Fig. 6a shows the TEM analysis of the synthesized AgNPs prepared by plant leaf extracts of P. pterocarpum in the current study. The synthesized AgNPs was found to be polydispersed in nature, spherical in shape with an average size ranging between 30 and $50 \mathrm{~nm}$. A similar observation was recorded by various researchers regarding the shape and size of AgNPs of about $10.4 \mathrm{~nm}$ [35], $34 \mathrm{~nm}$ [5], and $35 \mathrm{~nm}$ [18]. Fig. 6b shows the energy dispersive spectrum of the synthesized AgNPs using $P$. pterocarpum leaf extracts. The spectrum shows a typical strong signal peak at $3 \mathrm{keV}$, which confirms the presence of silver due to surface plasmon resonance, which is similar to earlier reported studies [36,37]. EDX analysis was performed to confirm the elemental composition of nanoparticles formation. Earlier reports also found the major peaks of silver in the EDX analysis, which confirms the formation of AgNPs using plant extract of Artocarpus heterophyllus seed extracts [38].

\section{DLS and zeta potential analysis of synthesized AgNPS}

The size distribution of synthesized AgNps was analyzed using DLS technique. The results show that the average distribution size of the synthesized AgNps was found to be $44.77 \mathrm{~nm}$ (Fig. 7). A few particles size with distribution at lower range indicate the formation of AgNPs synthesis with lower particle size. The size of nanoparticles formation depends on the several key factors such as $\mathrm{pH}$, temperature, substrate concentration, and time of exposure to the substrate. Different size and shapes of AgNPs synthesized by plant have been reported in previous studies. The present results were in good agreement with the earlier reports reported in literature $[5,22,39]$.

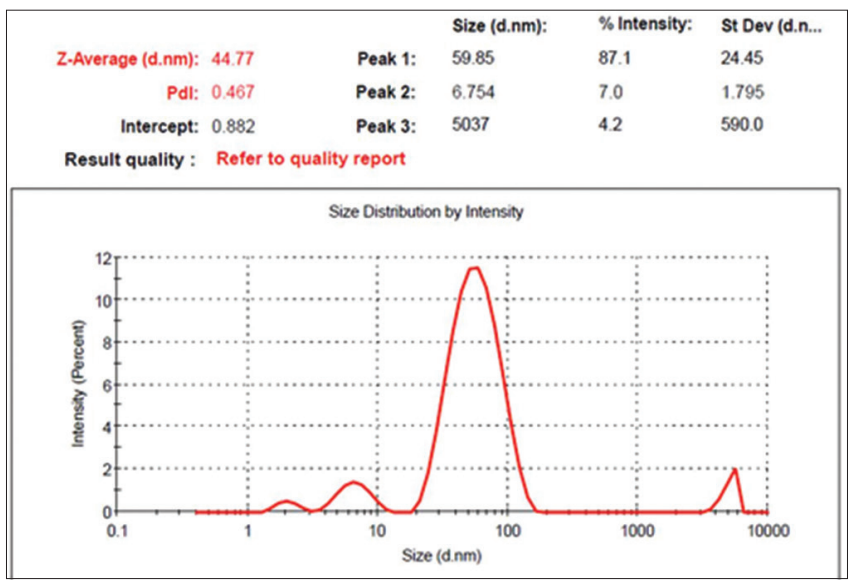

Fig. 7: Dynamic light scattering analysis of synthesized silver nanoparticles

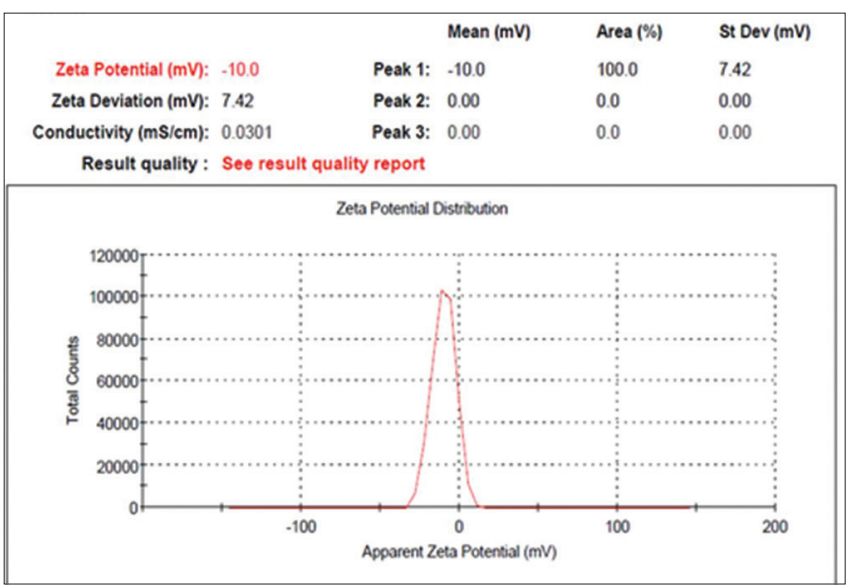

Fig. 8: Zeta potential analysis of synthesized silver nanoparticles 


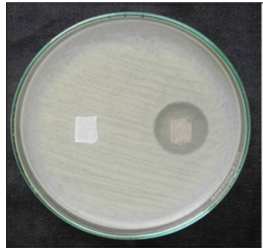

Bacillus subtilis

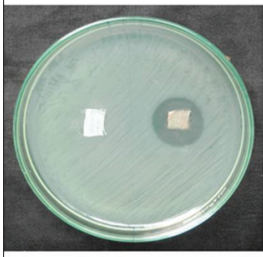

Pseudomonas aeruginose

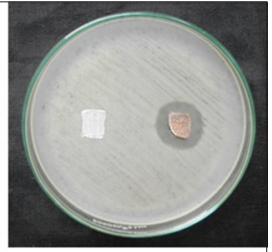

Staphylococcus aureus

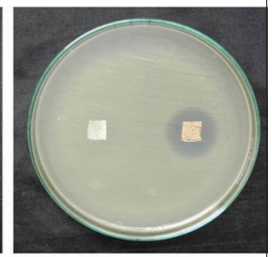

Escherichia coli
Fig. 9: Antibacterial activity of the cotton fabric incorporated with silver nanoparticles

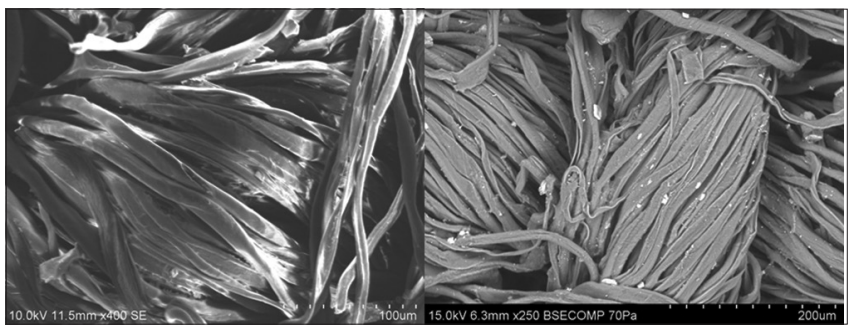

Fig. 10: Scanning electron microscope analysis of untreated and cotton fabric incorporated with silver nanoparticles
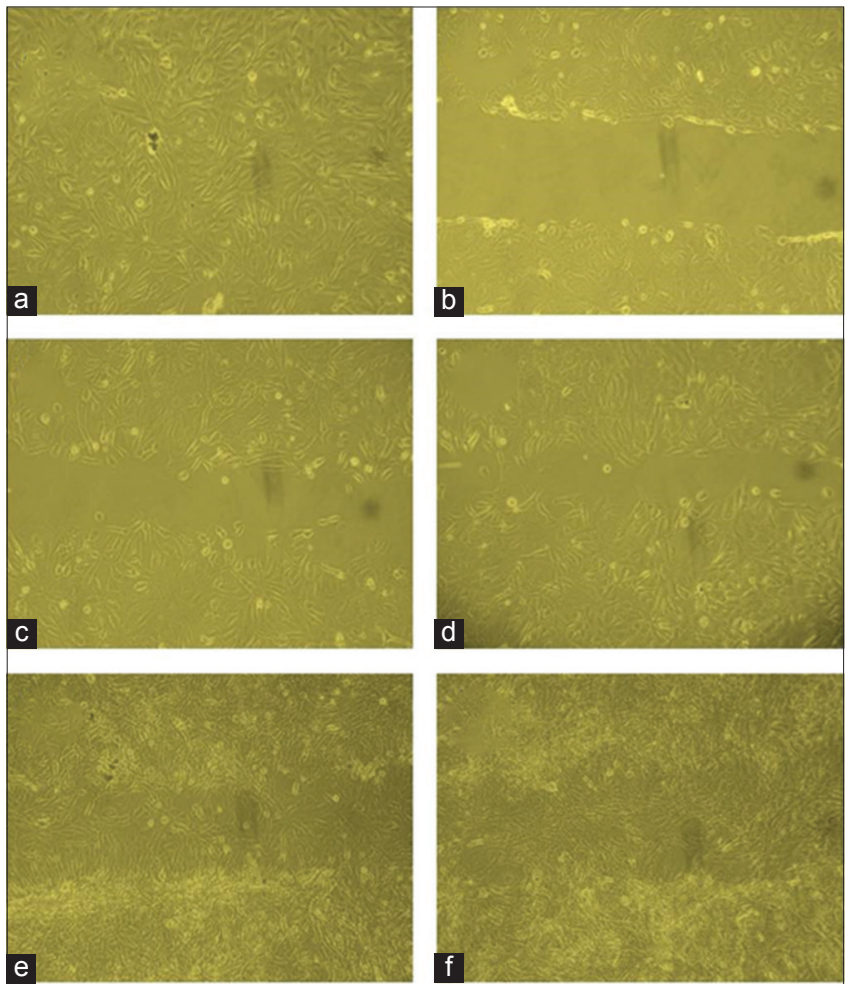

(a) Normal cells, (b) wounded cells, (c) $24 \mathrm{hrs} \mathrm{(31.57 \% ),} \mathrm{(d)} 48 \mathrm{hrs}$ (52.63\%), (e) 72 hrs (89.47\%), (f) 96 hrs $(99.47 \%)$.

Fig. 11: In vitro wound scratch of silver nanoparticles against fibroblast 3T3 cells
Fig. 8 shows the zeta potential measurement for the AgNPs synthesized using P. pterocarpum. Zeta potential is one of the important parameters for analyzing the properties of the nanoparticle surface and also determining the stability of the dispersion. Previous studies have corroborated that zeta potential measurement showing values more than $+25 \mathrm{mV}$ or $<-25 \mathrm{mV}$ may have a good degree of stability [40]; further, the negative charge on the AgNPs ions may also be influenced by the presence of biomolecules obtained from the plant extracts [41]. In our study, the zeta potential value of the dispersed AgNPs was found to be $-10 \mathrm{mV}$ which is similar to the earlier reported studies [35,39].

\section{Antibacterial activity of AgNPs-cotton fabric}

The antimicrobial properties of AgNPs have been widely utilized in various areas such as medicine, food packaging, health-related industry, antiseptic formulation, wound care dressing, and also in various environmental applications [42]. Since ancient times, the application of silver and its associated components as potential antimicrobial agents have been extensively used for preserving the water in the form of silver coins or silver coated vessels $[43,44]$. In the earlier study, the AgNPs synthesized using P. pterocarpum were successfully tested for their antimicrobial property against various pathogens [17]. In the present study, the potential AgNPs were further incorporated on cotton fabrics and tested for their antimicrobial efficiency against four different pathogenic strains, namely, S. aureus (MTCC-96), B. subtilis (MTCC-441), E. coli (MTCC-443), and P. aeruginosa (MTCC-1688).

The antibacterial activity of the cotton treated with the AgNPs synthesized using plant extract was determined based on the zone of inhibition against the tested pathogens (Fig. 9). The untreated control fabric did not show the zone of inhibition around the fabric material. The fabrics incorporated with AgNPs showed a clear zone of inhibition around the cotton fabric against all the tested pathogenic bacterial strains which confirm their efficiency. The bacterial growth inhibition on agar plates revealed the biocidal activity of AgNPs cotton fabric. In the present study, Gram-positive and Gram-negative bacteria were used for assessing the antibacterial activity of AgNPs-cotton fabric. Interestingly, the fabric coated with AgNPs inhibits the growth of both types of bacteria. Similar results have already been reported in previous studies for AgNPs synthesized from different sources, which was coated on cotton fabric [45-48].

The cotton fabrics coated with nanosilver were evaluated for its antibacterial efficacy and the nanosilver coated fabric shows a good antimicrobial property against both Gram-positive and Gram-negative bacteria [49]. Similarly, El-Shishtawy et al. investigated the cotton fabrics coated with AgNps against different pathogenic strains [50]. The AgNPs have the tendency to attach to the cell surface and disturb the membrane integrity and causes the dysfunction of permeability and respiration. Moreover, the AgNPs could penetrate the cell and interact with sulfur or phosphorus containing molecules in the cell such as DNA and amino acids in protein; subsequently, cell damage occurred [51]. The untreated and AgNPs incorporated cotton fabrics were further characterized using SEM, which revealed the presence of AgNPs on the surface of the cotton fabrics (Fig. 10). This confirms the successful incorporation of AgNps on cotton fabrics, which in accordance with the existing reported literature [19,52].

\section{In vitro wound scratch assay}

AgNPs could influence cytokine production and possess the antiinflammatory properties [53]. In the present study, the synthesized AgNPs were tested for wound healing activity using fibroblast 3T3 cells. Fibroblast cells are commonly used to study cell proliferation. The wounded cells were exposed to $60 \mu \mathrm{g} / \mathrm{mL}$ green synthesized AgNPs at the different time such as $24,48,72$, and $96 \mathrm{~h}$ at $37^{\circ} \mathrm{C}$. The treated cells after periodic incubation were observed and analyzed for their wound recovery and growth of the fibroblast cells. At $24 \mathrm{~h}$ of AgNPs exposure, cell migration occurred at $31.57 \%$ in wounded cells. Fig. 11 reveals 
the effect of an increase in AgNPs exposure period increases the cell migration in fibroblast 3T3cells from $48 \mathrm{~h}$ (52.63\%), $72 \mathrm{~h}(89.47 \%)$, and $96 \mathrm{~h}(99.47 \%)$. The AgNPs loaded with hydrogel increases the cell migration in fibroblasts cell after $48 \mathrm{~h}$ [54]. After the scratch, the increase in a number of fibroblasts might be the reason for fibroblast migration or proliferation. Expression of contractile elements in fibroblasts induced by fibroblast transition to myofibroblasts and promotes cell migration. The AgNPs could drive the differentiation of fibroblasts into myofibroblasts and also promotes the wound contraction [55].

\section{CONCLUSION}

Herein, we provide the antibacterial and wound healing potential of AgNPs synthesized using plant leaf extracts of $P$. pterocarpum. The results recorded were significant; however, further knowledge on the biological effects of AgNPs on different bacterial strains will provide a vital information for the utilization of AgNPs as an antibacterial agent for medical applications.

\section{ACKNOWLEDGMENTS}

The authors greatly acknowledge the support provided by the Director, CAS in Botany, University of Madras, Chennai, for the laboratory facilities. We also thank NCNSNT, University of Madras, for providing permission for characterization studies.

\section{AUTHORS' CONTRIBUTIONS}

Annamalai P designed and carried out the experimental work, Kalaichelvan PT supervised the work. Annamalai P and Balashanmugam $P$ involved in manuscript editing, and all the authors have read and approved the final version of the manuscript.

\section{CONFLICTS OF INTEREST}

All the authors have declared that they have no conflicts of interest.

\section{REFERENCES}

1. Ali MS, Altaf M, Al-Lohedan HA. Green synthesis of biogenic silver nanoparticles using Solanum tuberosum extract and their interaction with human serum albumin: Evidence of "corona" formation through a multi-spectroscopic and molecular docking analysis. J Photochem Photobiol B 2017;173:108-19.

2. Nakkala JR, Mata R, Gupta AK, Sadras SR. Biological activities of green silver nanoparticles synthesized with Acorus calamus rhizome extract. Eur J Med Chem 2014;85:784-94.

3. Mohapatra B, Kuriakose S, Mohapatra S. Rapid green synthesis of silver nanoparticles and nanorods using Piper nigrum extract. J Alloys Compd 2015;637:119-26.

4. Murugesan S, Bhuvaneswari S, Sivamurugan V. Green synthesis, characterization of silver nanoparticles of a marine red alga Spyridia fusiformis and their antibacterial activity. Int J Pharm Pharm Sci 2017;9:192-7.

5. Ahmed S, Ahmad M, Swami BL, Ikram S. Green synthesis of silver nanoparticles using Azadirachta indica aqueous leaf extract. J Radiat Res Appl Sci 2016;9:1-7

6. Kulkarni N, Muddapur U. Biosynthesis of metal nanoparticles: A review. J. Nanotechnol 2014;2014:8.

7. Li S, Shen Y, Xie A, Yu X, Qiu L, Zhang L, et al. Green synthesis of silver nanoparticles using Capsicum annuиm L. Extract. Green Chem 2007;9:852-8

8. Doughari JH. Phytochemicals: Extraction methods, basic structures and mode of action as potential chemotherapeutic agents. In Phytochemicals-A Global Perspective of their Role in Nutrition and Health. United Kingdom: Intech Open; 2012.

9. Lo SF, Hayter M, Chang CJ, Hu WY, Lee LL. A systematic review of silver-releasing dressings in the management of infected chronic wounds. J Clin Nurs 2008;17:1973-85.

10. Wani IA, Ahmad T, Manzoor N. Size and shape dependant antifungal activity of gold nanoparticles: A case study of candida. Colloids Surf B Biointerfaces 2013;101:162-70.

11. Martinez-Gutierrez F, Olive PL, Banuelos A, Orrantia E, Nino N, Sanchez EM, et al. Synthesis, characterization, and evaluation of antimicrobial and cytotoxic effect of silver and titanium nanoparticles.
Nanomedicine 2010;6:681-8

12. Vigneshwaran N, Kumar S, Kathe AA, Varadarajan PV, Prasad V. Functional finishing of cotton fabrics using zinc oxide soluble starch nanocomposites. Nanotechnology 2006;17:5087.

13. Lansdown AB. Silver 2: Toxicity in mammals and how its products aid wound repair. J Wound Care 2002;11:173-7.

14. Xu B, Niu M, Wei L, Hou W, Liu X. The structural analysis of biomacromolecule wool fiber with Ag-loading $\mathrm{SiO} 2$ nanoantibacterial agent by UV radiation. J Photochem Photobiol A Chem 2007:188:98-105.

15. Chen X, Schluesener HJ. Nanosilver: A nanoproduct in medical application. Toxicol Lett 2008;176:1-2.

16. Montazer M, Alimohammadi F, Shamei A, Rahimi MK. In situ synthesis of nano silver on cotton using tollens' reagent. Carbohydr Polym 2012;87:1706-12

17. Annamalai P, Balashanmugam P, Kalaichelvan P. Biogenic synthesis silver nanoparticles using Peltophorum pterocarpum leaf extracts and its antimicrobial efficacy against selective pathogens. Int J Appl Pharm 2018:10;107-11.

18. Veerasamy R, Xin TZ, Gunasagaran S, Xiang TF, Yang EF, Jeyakumar N, et al. Biosynthesis of silver nanoparticles using mangosteen leaf extract and evaluation of their antimicrobial activities. J Saudi Chem Soc 2011;15:113-20.

19. Balashanmugam P, Kalaichelvan PT. Biosynthesis characterization of silver nanoparticles using Cassia roxburghii DC. Aqueous extract, and coated on cotton cloth for effective antibacterial activity. Int J Nanomedicine 2015;10 Suppl 1:87-97.

20. Liang CC, Park AY, Guan JL. In vitro scratch assay: A convenient and inexpensive method for analysis of cell migration in vitro. Nat Protoc 2007;2:329-33.

21. Felice F, Zambito Y, Belardinelli E, Fabiano A, Santoni T, Di Stefano R, et al. Effect of different chitosan derivatives on in vitro scratch wound assay: A comparative study. Int J Biol Macromol 2015;76:236-41.

22. Chung IM, Park I, Seung-Hyun K, Thiruvengadam M, Rajakumar G. Plant-mediated synthesis of silver nanoparticles: Their characteristic properties and therapeutic applications. Nanoscale Res Lett 2016;11:40.

23. Sathishkumar G, Gobinath C, Karpagam K, Hemamalini V, Premkumar K, Sivaramakrishnan S, et al. Phyto-synthesis of silver nanoscale particles using Morinda citrifolia L. And its inhibitory activity against human pathogens. Colloids Surf B Biointerfaces 2012;95:235-40.

24. Dipankar C, Murugan S. The green synthesis, characterization and evaluation of the biological activities of silver nanoparticles synthesized from Iresine herbstii leaf aqueous extracts. Colloids Surf B Biointerfaces 2012;98:112-9.

25. Khan Z, Hussain JI, Hashmi AA. Shape-directing role of cetyltrimethylammonium bromide in the green synthesis of agnanoparticles using neem (Azadirachta indica) leaf extract. Colloids Surf B Biointerfaces 2012;95:229-34.

26. Singhal G, Bhavesh R, Kasariya K, Sharma AR, Singh RP. Biosynthesis of silver nanoparticles using Ocimum sanctum (Tulsi) leaf extract and screening its antimicrobial activity. J Nanopart Res 2011;13:2981-8.

27. Rao YS, Kotakadi VS, Prasad TN, Reddy AV, Gopal DV. Green synthesis and spectral characterization of silver nanoparticles from lakshmi tulasi (Ocimum sanctum) leaf extract. Spectrochim Acta A Mol Biomol Spectrosc 2013;103:156-9.

28. Ahmed S, Ikram S. Silver nanoparticles: One pot green synthesis using Terminalia arjuna extract for biological application. J Nanomed Nanotechnol 2015;6:309.

29. Aswathy Aromal S, Philip D. Green synthesis of gold nanoparticles using Trigonella foenum-graecum and its size-dependent catalytic activity. Spectrochim Acta A Mol Biomol Spectrosc 2012;97:1-5.

30. Dubey SP, Lahtinen M, Särkkä H, Sillanpää M. Bioprospective of Sorbus aucuparia leaf extract in development of silver and gold nanocolloids. Colloids Surf B Biointerfaces 2010;80:26-33.

31. Obaid AY, Al-Thabaiti SA, El-Mossalamy EH, Al-Harbi LM, Khan Z. Extracellular bio-synthesis of silver nanoparticles. Arab J Chem 2017;10:226-31.

32. Rahi DK, Parmar AS, Tiwari V. Biosynthesis of silver nanoparticles from fungal root endophytes of Sida acuta plant and evaluation of their antibacterial and antibiotic enhancing activity. Int J Pharm Pharm Sci 2014;6:160-6.

33. Khalil MM, Ismail EH, El-Baghdady KZ, Mohamed D. Green synthesis of silver nanoparticles using olive leaf extract and its antibacterial activity. Arab J Chem 2014;7:1131-9.

34. Song JY, Kim BS. Rapid biological synthesis of silver nanoparticles using plant leaf extracts. Bioprocess Biosyst Eng 2009;32:79-84. 
35. Sangeetha J, Sandhya J, Philip J. Biosynthesis and functionalization of silver nanoparticles using Nigella sativa, Dioscorea alata and Ferula asafoetida. Sci Adv Mater 2014;6:1681-90.

36. Kaviya S, Santhanalakshmi J, Viswanathan B, Muthumary J, Srinivasan K. Biosynthesis of silver nanoparticles using Citrus sinensis peel extract and its antibacterial activity. Spectrochim Acta A Mol Biomol Spectrosc 2011;79:594-8.

37. Das J, Paul Das M, Velusamy P. Sesbania grandiflora leaf extract mediated green synthesis of antibacterial silver nanoparticles against selected human pathogens. Spectrochim Acta A Mol Biomol Spectrosc 2013;104:265-70.

38. Vijayakumar M, Priya K, Nancy FT, Noorlidah A, Ahmed AB. Biosynthesis, characterisation and anti-bacterial effect of plantmediated silver nanoparticles using Artemisia nilagirica. Ind Crop Prod 2013;41:235-40

39. Heydari R, Rashidipour M. Green synthesis of silver nanoparticles using extract of oak fruit hull (jaft): Synthesis and in vitro cytotoxic effect on mcf-7 cells. Int J Breast Cancer 2015;2015:846743.

40. Sukirtha R, Priyanka KM, Antony JJ, Kamalakkannan S, Thangam R, Gunasekaran P, et al. Cytotoxic effect of green synthesized silver nanoparticles using Melia azedarach against in vitro HeLa cell lines and lymphoma mice model. Process Biochem 2012;47:273-9.

41. Khatoon N, Mazumder JA, Sardar M. Biotechnological applications of green synthesized silver nanoparticles. J Nanosci Curr Res 2017;2:107.

42. Gao X, Yourick JJ, Topping VD, Black T, Olejnik N, Keltner Z, et al. Toxicogenomic study in rat thymus of F1 generation offspring following maternal exposure to silver ion. Toxicol Rep 2015;2:341-50.

43. Devi LS, Joshi SR. Ultrastructures of silver nanoparticles biosynthesized using endophytic fungi. J Microsc Ultrastruct 2015;3:29-37.

44. Padalia H, Moteriya P, Chanda S. Green synthesis of silver nanoparticles from marigold flower and its synergistic antimicrobial potential. Arab J Chem 2015;8:732-41.

45. Pannerselvam B, Dharmalingam Jothinathan MK, Rajenderan M, Perumal $\mathrm{P}$, Pudupalayam Thangavelu $\mathrm{K}$, Kim $\mathrm{HJ}$, et al. An in vitro study on the burn wound healing activity of cotton fabrics incorporated with phytosynthesized silver nanoparticles in male Wistar albino rats. Eur J Pharm Sci 2017;100:187-96.

46. Hebeish A, El-Naggar ME, Fouda MM, Ramadan MA, Al-Deyab SS, El-Rafie MH. Highly effective antibacterial textiles containing green synthesized silver nanoparticles. Carbohydr Polym 2011;86:936-40.

47. Wu M, Ma B, Pan T, Chen S, Sun J. Silver-nanoparticle-colored cotton fabrics with tunable colors and durable antibacterial and self-healing superhydrophobic properties. Adv Funct Mater 2016;26:569-76.

48. Sana SS, Badineni VR, Arla SK, Boya VK. Eco-friendly synthesis of silver nanoparticles using leaf extract of Grewia flaviscences and study of their antimicrobial activity. Mater Lett 2015;145:347-50.

49. El-Rafie MH, Ahmed HB, Zahran MK. Characterization of nanosilver coated cotton fabrics and evaluation of its antibacterial efficacy. Carbohydr Polym 2014;107:174-81.

50. El-Shishtawy RM, Asiri AM, Abdelwahed NA, Al-Otaibi MM. In situ production of silver nanoparticle on cotton fabric and its antimicrobial evaluation. Cellulose 2011;18:75-82.

51. Raffi M, Hussain F, Bhatti TM, Akhter JI, Hameed A, Hasan MM. Antibacterial characterization of silver nanoparticles against E. coli ATCC-15224. J Mater Res Sci Technol 2008;24:192-6.

52. Zahran MK, Ahmed HB, El-Rafie MH. Surface modification of cotton fabrics for antibacterial application by coating with AgNPs-alginate composite. Carbohydr Polym 2014;108:145-52.

53. Tian J, Wong KK, Ho CM, Lok CN, Yu WY, Che CM, et al. Topical delivery of silver nanoparticles promotes wound healing. ChemMedChem 2007;2:129-36.

54. Neibert K, Gopishetty V, Grigoryev A, Tokarev I, Al-Hajaj N, Vorstenbosch $\mathrm{J}$, et al. Wound-healing with mechanically robust and biodegradable hydrogel fibers loaded with silver nanoparticles. Adv Healthc Mater 2012;1:621-30.

55. Liu X, Lee PY, Ho CM, Lui VC, Chen Y, Che CM, et al. Silver nanoparticles mediate differential responses in keratinocytes and fibroblasts during skin wound healing. ChemMedChem 2010;5:468-75. 